\title{
The Effect of Diazoxide-induced Hormonal Secretion on Plasma Triglyceride Concentration in the Rat
}

\author{
R. P. Eaton and D. S. Schade \\ University of New Mexico School of Medicine, Department of Medicine, Albuquerque, New Mexico, USA
}

\begin{abstract}
Summary. The relationship between non-esterified fatty acid (NEFA) mobilization and hepatic conversion to plasma triglycerides (TG), as modulated by diazoxide-induced effects upon endogenous catecholamine, glucagon, and insulin secretion, was examined in vivo in the rat. Thyrotropin (TSH)induced NEFA mobilization provided the control study. - In all control experiments, TSH (1.5 IU/ $100 \mathrm{~g}$ ) induced a $110 \%$ increase in NEFA availability, which was associated with a subsequent $52 \%$ increase in plasma $\mathrm{TG}$ concentration and a $73 \%$ increase in plasma ketone bodies. Following diazoxide administration $(30 \mathrm{mg} / \mathrm{kg})$, endogenous secretion of both catecholamines and glucagon was observed, resulting in a comparable $100 \%$ increase in NEFA availability, with the appropriate ketonaemic response. However, in contrast to the control TSH study, plasma triglyceride concentration did not increase. This suppression was secondary, at least in part, to a direct $40 \%$ inhibition of hepatic secretion of triglycerides. - Although plasma NEFA concentration is an important determinant of plasma triglyceride levels, the concurrent concentration of endogenous catecholamines, glucagon, and insulin modulate the hepatic conversion of NEFA to triglycerides in vivo.
\end{abstract}

Key words: Diazoxide, TSH, rat, triglyceride, non esterified fatty acid (NEFA), ketone bodies, glucagon, catecholamines, insulin.

The contribution of the endogenous hormonal milieu to non-esterified fatty acid (NEFA) metabolism is not resolved. The present investigation was designed to examine the effect of endogenous catecholamine, glucagon, and insulin secretion upon NEFA conversion to triglycerides within the intact animal. Traditional concepts of catecholamine and glucagon influence upon lipid regulation have emphasized the role of stimulation of peripheral NEFA mobilization from adipose tissue with a secondary induction of fatty liver, hyperlipoproteinaemia [1] and hyperketonaemia $[2,3]$. The possibility of other hormonal effects upon NEFA metabolism has been suggested by the demonstration in vitro in the perfused rat liver, confirmed by isotopic tracer studies in man, that fractional conversion of NEFA to triglyceride may be decreased by epinephrine and/or glucagon [4-6].

We have investigated the triglyceride and ketone body response to controlled NEFA availability in the presence and absence of excess endogenous catecholamine and glucagon secretion in the intact rat. Thyrotropin (TSH) injection was utilized to mobilize NEFA in the control studies in the absence of endogenous catecholamine and glucagon secretion. Diazoxide, a stimulus for adrenal catecholamine $[7,8]$ and pancreatic glucagon secretion [9], as well as for inhibition of insulin secretion [8], was utilized to mobilize NEFA in the presence of physiological increments in endogenous catecholamines and glucagon. NEFA availability during both thyrotropin stimulation and diazoxide challenge were comparable, providing an opportunity for appropriate comparisons in the presence and absence of hormone excess.

\section{Methods}

Male Sprague-Dawley rats weighing $180-200 \mathrm{~g}$ were used in all experiments. Animals were studied at $0800 \mathrm{~h}$ in the fed state having had access to Purina rat chow and water ad lib. The study 
comprised 82 animals, divided into three paired groups, providing a control group, a thyrotropin-induced NEFA mobilization group and a diazoxide-induced catecholamine and glucagon stimulation group.

For the assay of plasma norepinephrine and epinephrine, a $1 \mathrm{ml}$ sample of blood was obtained by cardiac puncture in lightly ether-anaesthetized animals. The blood was placed in an heparinized tube containing reduced glutathione at a final concentration of $5 \mathrm{mM}$, immediately centrifuged, and the plasma frozen at $-20^{\circ} \mathrm{C}$ until assay within ten days. Plasma epinephrine and norepinephrine were assayed with a sensitivity of $0.5 \mathrm{ng} / \mathrm{ml}$ and a precision of $\pm 10 \%$ according to the radioenzymatic method of Peuler and Johnson [10], with the thin layer chromatography modifications of DaPrada and Zurcher [11].

All other chemical determinations were performed on plasma samples obtained by decapitation of the lightly ether-anaesthetized animals, with collection of the blood in heparinized test tubes at $5^{\circ} \mathrm{C}$ containing benzamidine, as previously reported [12]. All samples were assayed for insulin [13], glucagon [12], thyroxine [14], NEFA [15], betahydroxybutyrate $(\mathrm{BOH})$ and acetoacetate (AcAc) [16], glucose [17], and triglycerides [18]. The ketone bodies were assayed on the day the experiments were performed.

\section{Thyrotropin (TSH) Stimulation}

To stimulate endogenous NEFA mobilization without stimulating catecholamine or glucagon secretion, TSH (Thyropar, Armour) was diluted in $4 \mathrm{ml}$ of normal saline, and animals were given $1.5 \mathrm{IU} / 100 \mathrm{~g}$ body weight under light ether anaesthesia by intraperitoneal injection. Ten animals were sacrificed at time zero and six animals thereafter at $30,45,60$, and 90 minutes after TSH injection.

\section{Diazoxide Stimulation}

To stimulate endogenous NEFA mobilization in association with enhanced endogenous catecholamine and glucagon secretion, diazoxide (Hyperstat, Shering, Bloomfield, NJ) $(30 \mathrm{mg} / \mathrm{kg}$ body weight) was administered by stomach tube. The animals receiving diazoxide were studied in parallel with those receiving TSH to eliminate variables in diet and environment. The ten animals sacrificed at time zero served as basal controls for the TSH, diazoxide and saline control studies. Thereafter, six additional animals were sacrificed at 30, 45,60, and 90 min after diazoxide administration.

\section{Saline Control Studies}

A separate saline control group was performed in parallel with the TSH and diazoxide groups. Following the administration of $4 \mathrm{ml}$ of $0.154 \mathrm{~mol} / 1$ saline, six animals were sacrificed at $30,45,60$, and $90 \mathrm{~min}$., and the plasma assayed as above.

\section{Triglyceride Production In Vivo}

In separate experiments, triglyceride production rates were determined using the Triton method described by Robertson et al. [19]. Triton WR-139 (polymeric-p-iso-octyl polyoxythylene phenol) was injected via a foot vein at a concentration of $300 \mathrm{mg} / \mathrm{ml}$, under light ether anaesthesia. Animals weighing approximately $200 \mathrm{~g}$ received a total dose of $135 \mathrm{mg}$, which results in maximal inhibition of triglyceride removal from the blood [19]. Serial retro-orbital blood samples $(0.5 \mathrm{ml})$ were obtained prior to Triton injection and at $15 \mathrm{~min}$ intervals thereafter, and immediately placed in heparinized plasma tubes at $5^{\circ} \mathrm{C}$. Four animals were studied following the intragastric administration of diazoxide or intraperitoneal injection of TSH as described above. Triglyceride secretion rate (TGSR) was calculated from the plasma volume $\left(\mathrm{PV}_{\mathrm{e}}\right)$ determined by Evans Blue Dye injection in Sprague-Dawley rats according to the relationship: TGSR $=$ slope $\times \mathrm{PV}_{\mathrm{e}}$. In our dye injection studies, $\mathrm{PV}_{\mathrm{e}}=0.03 \times$ wt. +4.01 .

The diazoxide data were compared to the data from the TSH treated rats, and differences in study means analyzed by Student's " $t$ " test. The TG slopes were compared utilizing an analysis of variance as applied to regression [20].

\section{Results}

\section{Control Saline Study}

To exclude substrate or hormonal change unrelated to either TSH or diazoxide exposure, control studies were performed in 30 rats. In rats given saline, there was no consistent alteration in plasma glucagon (127 $\pm 13 \mathrm{pg} / \mathrm{ml})$, glucose $(181 \pm 24 \mathrm{mg} / \mathrm{dl})$, NEFA $(0.51$ $\pm 0.03 \mathrm{mmol} / \mathrm{l})$, total ketone bodies $(0.29 \pm$ $0.5 \mathrm{mmol} / 1)$, or triglyceride concentration (125 \pm $8 \mathrm{mg} / \mathrm{dl}$ ). A slight reduction in circulating levels of insulin (from $16 \pm 4$ to $13 \pm 4 \mu \mathrm{U} / \mathrm{mi}$ ) and of catecholamines (from $2.44 \pm 0.22$ to $1.28 \pm 0.14 \mathrm{ng}$ / ml) was observed.

\section{Effect of TSH \\ on Non-esterified Fatty Acid Mobilization and Plasma Ketone Body and Triglyceride Levels}

Hormonal Response (Table 1). Basal concentrations of total plasma catecholamines $(2.37 \pm 0.45 \mathrm{ng} / \mathrm{ml})$ were not significantly altered by TSH injection. Similarly, plasma glucagon concentration $(180 \pm 11 \mathrm{pg} /$ $\mathrm{ml}$ pre-TSH) was unaltered by TSH injection, while plasma insulin concentration rose from basal levels of $16 \pm 2 \mu \mathrm{U} / \mathrm{ml}$ to $24 \pm 3 \mu \mathrm{U} / \mathrm{ml}(\mathrm{p}<0.05) 60$ minutes after TSH. Plasma thyroxine levels $(5 \pm$ $3 \mu \mathrm{g} / \mathrm{dl}$ ) were unaltered by acute TSH injection.

Lipid and Metabolite Response (Fig. 1). A brisk lipolytic response was observed which was maximal at 60 minutes post TSH (pre-TSH NEFA level, 0.49 $\pm \quad 0.03 \mathrm{mmol} / 1$; maximal post-TSH; $1.18 \pm$ $0.140 \mathrm{mmol} / \mathrm{l}, \mathrm{p}<0.001)$. Plasma total ketone body concentration rose promptly in parallel with the rise in NEFA, from basal levels of $0.26 \pm 0.02 \mathrm{mmol} / 1$ to a maximum of $0.45 \pm 0.08 \mathrm{mmol} / 1(\mathrm{p}<0.001)$ at 60 minutes. Both 3-hydroxybutyrate and acetoacetate responded in a comparable fashion to this ketogenic response (data not shown). Plasma triglyceride concentration rose from basal levels of $142 \pm 10 \mathrm{mg} / \mathrm{dl}$ to a maximum of $217 \pm 20 \mathrm{mg} / \mathrm{dl}(\mathrm{p}<0.001)$, also at 60 minutes after TSH. 
Table 1. Hormonal responses to TSH and diazoxide

\begin{tabular}{|c|c|c|c|}
\hline Minutes & $\begin{array}{l}\text { Glucagon } \\
(\mathrm{pg} / \mathrm{ml})\end{array}$ & $\begin{array}{l}\text { Catecholamine } \\
(\mathrm{ng} / \mathrm{ml})\end{array}$ & $\begin{array}{l}\text { Insulin } \\
(\mu \mathrm{U} / \mathrm{ml})\end{array}$ \\
\hline & \multicolumn{3}{|c|}{ Response to TSH } \\
\hline $0 \quad n=10$ & $180 \pm 11$ & $2.37 \pm 0.45$ & $16 \pm 2$ \\
\hline $30 \mathrm{n}=6$ & $177 \pm 13$ & $2.35 \pm 0.39$ & $19 \pm 4$ \\
\hline $60 n=6$ & $213 \pm 19$ & $1.95 \pm 0.30$ & $22 \pm 3^{\mathrm{a}}$ \\
\hline \multirow[t]{2}{*}{$90 \mathrm{n}=6$} & $176 \pm 13$ & $2.15 \pm 0.43$ & $21 \pm 2^{a}$ \\
\hline & \multicolumn{3}{|c|}{ Response to diazoxide } \\
\hline $0 \mathrm{n}=10$ & $180 \pm 11$ & $2.37 \pm 0.45$ & $16 \pm 2$ \\
\hline $30 n=6$ & $387 \pm 33^{a}$ & $3.59 \pm 0.48$ & $19 \pm 4$ \\
\hline $60 \mathrm{n}=6$ & $256 \pm 55^{\mathrm{a}}$ & $6.17 \pm 0.96^{\mathrm{a}}$ & $5 \pm 3^{a}$ \\
\hline $90 \mathrm{n}=6$ & $155 \pm 26$ & $5.27 \pm 0.90^{\mathrm{a}}$ & $10 \pm 2$ \\
\hline
\end{tabular}

TSH ADMINISTRATION

NONESTERIFIED FATTY ACIDS
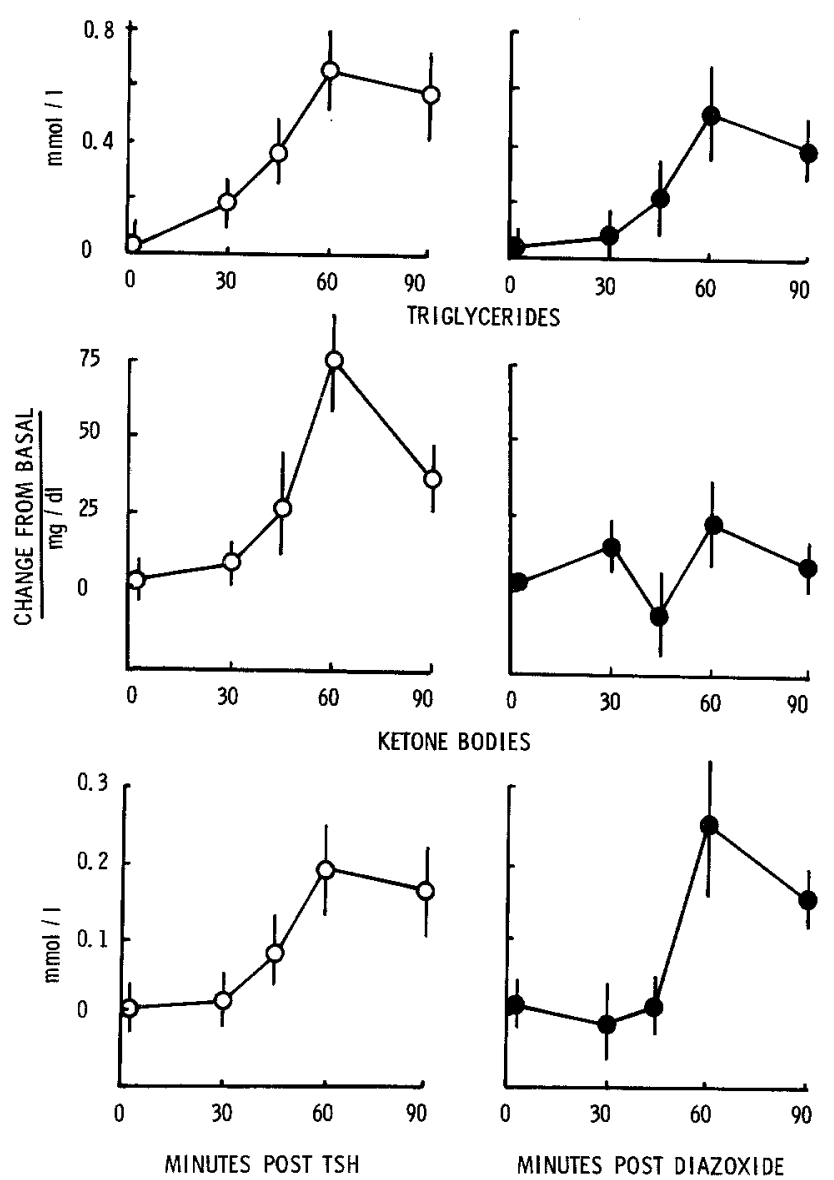

Fig. 1. Comparison of the effects of TSH and diazoxide administration upon the concentration of plasma NEFA (basal concentration $=0.48 \pm 0.03 \mathrm{mmol} / \mathrm{l}$ ), total ketone bodies (basal concentration $=0.26 \pm 0.02 \mathrm{mmol} / \mathrm{l}$ ), and triglycerides (basal concentration $=142 \pm 10 \mathrm{mg} / \mathrm{dl}$ ) in the rat. Plasma from the same ten animals as in Table I was analyzed at all time points. Data are presented as the mean \pm SEM change from baseline

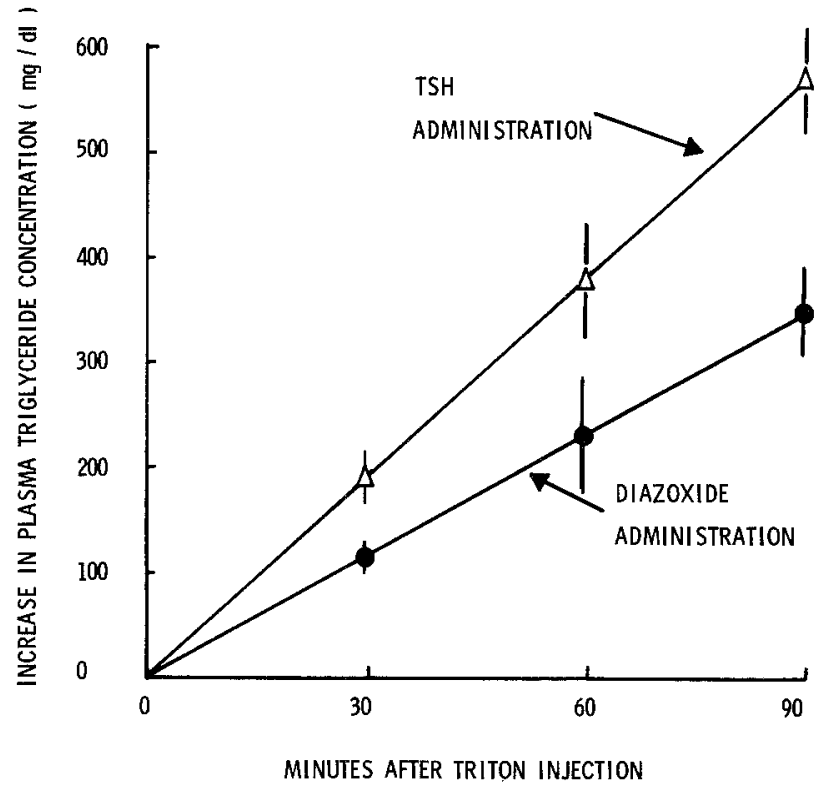

Fig. 2. Effect of TSH (- $\triangle-)$ and diazoxide (-0-) administration upon the Triton induced rise in plasma $\mathrm{TG}$ concentration from basal levels of $120 \pm 16 \mathrm{mg} / \mathrm{dl}$, as an estimate of hepatic TG production. The diazoxide-TG production rate determined from the slope $(Y=3.86 \mathrm{X}+64)$ was significantly less than the TSHTG production rate (slope: $\mathrm{Y}=4.36 \mathrm{X}+80(\mathrm{p}<0.01)$ ) as given in Results

No change in plasma glucose concentration was observed during the 90 minute period of observation (pre-TSH, $192 \pm 5 \mathrm{mg} / \mathrm{dl}$; maximum post-TSH, 208 $\pm 3 \mathrm{mg} / \mathrm{dl}, \mathrm{p}<0.05)$.

\section{Effect of Diazoxide on Fatty Acid Mobilization}

Hormonal Response (Table 1). The oral administration of diazoxide resulted in a rise in plasma catecholamine concentration from basal levels of $2.37 \pm 0.45 \mathrm{ng} / \mathrm{ml}$ to a maximum of $6.17 \pm 0.96 \mathrm{ng} /$ $\mathrm{ml}$ at 60 minutes $(\mathrm{p}<0.001)$. Epinephrine and norepinephrine both showed proportionate increases in concentration. Simultaneously, plasma glucagon concentration rose from pre-diazoxide levels of 180 $\pm 11 \mathrm{pg} / \mathrm{ml}$ to a maximum of $387 \pm 33 \mathrm{pg} / \mathrm{ml}(\mathrm{p}<$ $0.001) 30$ minutes postdiazoxide, while plasma insulin concentration fell from $16 \pm 1 \mu \mathrm{U} / \mathrm{ml}$ to $5 \pm$ $3 \mu \mathrm{U} / \mathrm{ml} 60$ minutes post-diazoxide $(\mathrm{p}<0.001)$.

Lipid and Metabolite Response (Fig.1). In response to diazoxide administration, plasma NEFA concentration rose from $0.49 \pm 0.03 \mathrm{mmol} / 1$ to a maximum of $1.01 \pm 0.11 \mathrm{mmol} / 1(\mathrm{p}<0.001) 60$ minutes postdiazoxide, comparable to the rise seen with TSH stimulation in the absence of excess catecholamine. Plasma ketone body concentration also rose from basal levels of $0.26 \pm 0.02 \mathrm{mmol} / 1$ to a maximum of 
$0.52 \pm 0.05 \mathrm{mmol} / \mathrm{l}(\mathrm{p}<0.001)$ at 60 minutes. The rise in endogenous catecholamine and glucagon secretion, with the associated reduction in insulin secretion, was accompanied by hyperglycaemia, with basal glucose levels rising from $192 \pm 4 \mathrm{mg} / \mathrm{dl}$ to a maximum of $323 \pm 39 \mathrm{mg} / \mathrm{dl}$ at 60 minutes. In contrast to the TSH study, there was no comparable rise in plasma triglyceride concentration (Fig. 1).

Triglyceride Production Studies. To investigate the mechanism of the diazoxide-induced inhibition of TG elevation in spite of increased NEFA availability (Fig. 2), TG production rates were examined in TSH versus diazoxide treated animals. Triton 1339 injection into TSH treated rats resulted in a brisk rise in plasma triglyceride concentration to maximum levels of $582 \pm 21 \mathrm{mg} / \mathrm{dl}$ (Fig. 2). In contrast, Triton 1339 injection into diazoxide treated rats resulted in a significantly smaller rise of plasma TG, with the maximum at 90 minutes being $311 \pm 26 \mathrm{mg} / \mathrm{dl}(\mathrm{p}<$ $0.001)$. The TGSR in TSH treated rats was $0.69 \pm$ $0.07 \mathrm{mg} / \mathrm{min}$, and was reduced by $40 \%$ to $0.41 \pm$ $0.09 \mathrm{mg} / \mathrm{min}(\mathrm{p}<0.01)$ in diazoxide treated rats.

\section{Discussion}

These investigations examined the quantitative role of regulatory hormones upon the conversion of NEFA into circulating triglycerides. The effects of physiological changes in the concentration of epinephrine, norepinephrine, and glucagon suggested that these hormones exerted a direct modulation of lipid production rates, such that the expected hyperlipaemia in response to NEFA mobilization was not observed.

The observations of Heimberg et al. [21, 5], which have been confirmed by other investigators in the perfused liver $[22,23,24]$, demonstrated the dependence of lipogenesis and of ketogenesis upon the concentration of NEFA entering the liver. In this setting, the addition of pharmacological amounts of catecholamines to the perfusate resulted in a reciprocal augmentation of ketone body generation and a simultaneous depression of triglyceride output from the liver [33]. Our data extend to the in vivo situation confirmation of a dependence of ketone and triglyceride production upon plasma NEFA concentration, demonstrated following TSH injection. They also demonstrate a regulatory role of catecholamines in concert with glucagon in limiting TG production following diazoxide administration. These data provide a potential hormonal mechanism for the previously reported TG lowering response to diazoxide therapy in man [40].
The present in vivo observations defining the quantitative TSH response relative to lipolytic, ketonaemic and lipaemic changes, extend observations obtained with this peptide since the 1950's. Previous studies of TSH examined its potency among pituitary peptides in promoting mobilization of NEFA in association with ketosis. The lipolytic response has been carefully defined by the studies of Freinkel [25] in rat adipose tissue in vitro, and the ketonaemic response described by Peterson et al. in 1955 [26] and by Engel et al. [27] in 1957. Our data extend these observations to quantitate the simultaneous elevation in plasma triglyceride concentration which occurs following TSH injection. While our data do not resolve the mechanism of this TG rise, it seems likely to represent the response to fatty acid mobilization which provides excess NEFA substrate to the liver for metabolism. The small elevation in plasma insulin concentration which was associated with TSH injection may also have contributed to the rise in TG concentration, since insulin has been proposed from indirect evidence in man [28] and by direct replacement in the diabetic rat [29] to enhance hepatic TG production.

In contrast to the $\mathrm{TSH}$ response, the augmented NEFA availability occurring with diazoxide-induced endogenous catecholamine and glucagon excess, resulted in a significant elevation in ketone body concentration without a simultaneous rise in plasma triglyceride levels. We have demonstrated that reduced hepatic production of TG contributed to the failure of plasma TG concentration to rise during endogenous catecholamine and glucagon mobilization of NEFA. Thus, our data support the concept that these endogenous hormones have the potential to reduce TG production even during periods of availability of excess NEFA, extending observations in the perfused liver.

It is difficult to separate direct effects of catecholamines from those of increased glucagon and reduced insulin secretion [30]. The secretion of catecholamines documented in our studies may be expected to influence NEFA mobilization, and to directly stimulate the secretion of glucagon [31]. Traditional concepts of catecholamine influence upon lipid regulation have emphasized this role of stimulation of peripheral NEFA mobilization from adipose tissue with a secondary, substrate-induced fatty liver [1] and hyperketonaemia [32, 3]. The possibility of other catecholamine effects upon fatty acid metabolism has been suggested by the demonstration in vitro in the perfused rat liver [33], confirmed by isotopic tracer studies in both man and the rat $[4,34]$, that fractional conversion of NEFA to TG may be reduced by epinephrine. Acute stress in the Sand Rat 
has been reported to induce an immediate decrease in endogenous triglyceride secretion and circulating triglyceride levels, which could be partially reproduced in vivo with epinephrine injection [35]. Moreover, in both the dog and the rat, with the persistent lipolytic response to chronically administered epinephrine, plasma TG levels remain normal while cholesterol levels rise $[36,37]$. Our data extend these studies of exogenous catecholamine injection to confirm a limitation of NEFA conversion to plasma TG by endogenous catecholamine, with an appropriate control study of NEFA mobilization in the absence of excess catecholamine.

The limitation of endogenous insulin secretion imposed by catecholamine secretion, as well as by diazoxide, may be expected to participate in the physiological responses to catecholamines and glucagon in vivo. This would permit peripheral lipolysis to evolve readily in response to lipolytic hormones, and would allow oxidation of fatty acid to ketones to be more readily expressed [22]. The concept of such a restraining role for insulin has recently been emphasized [38]. In this setting, it is attractive to relate the reduced TG production to the reduced ambient insulin levels, consistent with the suggestions by many investigators relating hyperinsulinemia with hepatic overproduction of lipids [19, 39, 40].

Participation of endogenously secreted glucagon in the limitation of NEFA conversion to TG has been previously proposed from observations in several species. In the duck, glucagon in pharmacological dosages has been reported to have a marked triglyceride lowering effect, which is dependent upon the presence of the liver [41]. In this bird, immediately upon cessation of glucagon administration, a marked rebound hypertriglyceridaemia occurs, which parallels the sustained NEFA elevation resulting from the earlier lipolytic response to glucagon. In the rat, glucagon excess has been reported to inhibit apolipoprotein protein formation in the isolated liver slice [42] and depress hepatic triglyceride synthesis [43]. Moreover, direct injection of glucagon in man and in the rat has been reported to result in a reduction in plasma lipid concentration $[44,45]$.

Interpretation of the in vivo responses to diazoxide must be made with caution, since unrecognized or undefined effects of the drug may influence the physiological response. Thus, alterations in regional blood flow as well as a general hypotensive response may participate in the metabolic effects, in addition to a contribution by catecholamine, glucagon, insulin, and of hyperglycaemia. The mechanisms of the physiological effects have been the subject of a recent symposium [46], but the total metabolic response has remained controversial [47]. Moreover, all of our data have been collected in the anaesthetized state, which may have also influenced hormone levels. In spite of these reservations, our data are consistent with in vivo rapid regulation of triglyceride production by catecholamines, glucagon, and insulin, which results in significant changes of circulatory levels of plasma triglycerides. Thus, these in vivo studies with parallel TSH and diazoxide stimulation of NEFA mobilization have provided an experimental approach to further define the hormonal regulation of lipid metabolism in which altered hepatic regulation of NEFA conversion to triglycerides may be observed.

Acknowledgements. This investigation was supported by grants from U. S. Public Health Service Grants 5 R01 HE 12085, 1 R01 AM 1868-01, $1 \mathrm{KZ} 4$ AM 00260-01, and the KROC Foundation. This study was completed with the excellent technical assistance of Enid Pinero, MT/ASCP, Jerry Towle, and Ingeborg Pommer.

\section{References}

1. Feigelson EB, Pfaff W, Karman A, Steinberg D (1961) The role of plasma free fatty acids in development of fatty liver. $\mathrm{J}$ Clin Invest 40: 2171-2179

2. Baker L, Kaye R, Hague N (1969) Metabolic homeostasis in juvenile diabetes mellitus. Diabetes 18: 421-427

3. Basso LV, Havel RJ (1970) Hepatic metabolism of free fatty acids in normal and diabetic dogs. J Clin Invest 49: 537-547

4. Eaton RP, Berman M, Steinberg D (1969) Kinetic studies of plasma free fatty acid and triglyceride metabolism in man. $\mathrm{J}$ Clin Invest 48: 1560-1579

5. Heimberg M, Weingstin E, Kohout M (1969) The effects of glucagon, dibutyryl cyclic AMP, and the concentration of free fatty acid on hepatic lipid metabolism. J Biochem 244: 531-539

6. Christiansen RZ (1977) Regulation of palmitate metabolism by carnitine and glucagon in hepatocytes isolated from fasted and carbohydrate refed rats. Biochim Biophys Acta 488: 249-262

7. Zarday A, Victoria J, Wolff F (1966) The effect of diazoxide on catecholamines. Metabolism 15: 257-261

8. Loubatières A, Mariani MM, Alric R (1968) The action of diazoxide on insulin secretion, medullo-adrenal secretion, and the liberation of catecholamines. Ann NY Acad Sci 150: 226-241

9. Eaton RP, Conway MJ, Schade DS (1976) Glucagon responsiveness in the genetically obese rat. Clin Res $116 \mathrm{~A}$

10. Pueler JC, Johnson FA (1977) Simultaneous single isotope radioenzymatic assay of plasma norepinephrine, epinephrine and dopamine. Life Sci 21: 625-636

11. Da Prada A, Zurcher G (1976) Simultaneous radioenzymatic determination of plasma and tissue adrenaline, noradrenaline and dopamine within the femtomole range. Life Sci 19: 1161-1174

12. Eaton RP (1973) Glucagon secretion and activity in the cobalt-chloride treated rat. Am J Physiol 225: 67-73

13. Hales CN, Randle PT (1963) Immunoassay of insulin and antibody precipitation. Biochem J 88: 137-146

14. Beckers C, Cornette C, Thalasso M (1973) Evaluation of serum thyroxine by radioimmunoassay. J Nucl Med 14: $317-320$ 
15. Schade DS, Burke G, Eaton RP, DeMoss J (1978) Semi-automated microscale extraction apparatus for assay of free fatty acids in plasma. Clin Chem 24: 1614-1615

16. Mellanby J, Williamson DH (1965) In: Bergmeyer HU (ed) Methods in enzymatic analysis, 2nd ed. Academic Press, New York, p 454-461

17. Huggett ASG, Nixon DA (1957) Use of glucose oxidase, peroxidase, and 0 -dianisidine in determination of blood and urinary glucose. Lancet II: $368-370$

18. Baculo G, David H (1973) Quantitative determination of serum triglyceride. Clin Chem 19: 476-478

19. Robertson RP, Gavareski DJ, Henderson JD, Porte DJr, Bierman EL (1973) Accelerated triglyceride secretion: A metabolic consequence of obesity. J Clin Invest 52: $1620-1626$

20. Armitage P (1974) Statistical methods in medical research. John Wiley and Sons, New York, p 269

21. Heimberg M, Van Harken DR, Weinstein I, Kohout M (1969) Regulatory factors in ketogenesis and in the metabolism of triglycerides by liver. Adv Exp Med Biol 4: 185-200

22. McGarry JD, Wright PH, Foster DW (1975) Hormonal control of ketogenesis. Rapid activation of hepatic ketogenic capacity in fed rats by anti-insulin serum and glucagon. J Clin Invest 55: 1202-1209

23. McGarry FD, Foster DW (1977) Hormonal control of ketogenesis: Biochemical considerations. Arch Intern Med 137: 495-501

24. Woodside WR, Heimberg H (1972) Hepatic metabolism of free fatty acids in experimental diabetes. Isr $\mathbf{J}$ Med Sci 8: 309-325

25. Freinkel N (1961) Extrathyroidal actions of pituitary thyrotropin: Effects on the carbohydrate, lipid, and respiratory metabolism of rat adipose tissue. J Clin Invest 40: 476-489

26. Peterson VP, Lotspeich WE (1955) Further aspects of the endocrine regulation of ketogenesis. Am J Physiol 182: 273-278

27. Engel FL, Engel MG, McPherson HT (1957) Ketogenic and adipokinetic activities of pituitary hormones. Endocrinology 61: 713-723

28. Olefsky JM, Farqhuar JW, Reaven GM (1975) Reappraisal of the role of insulin in hypertriglyceridemia. Am J Med 57: $551-556$

29. Reaven EP, Reaven GM (1974) Mechanisms for development of diabetic hypertriglyceridemia in streptozotocin-treated rats. Effects of diet and duration of insulin deficiency. J Clin Invest 54: $1167-1178$

30. Porte D Jr, Graber AL, Kuzuya T, Williams RH (1966) The effect of epinephrine on immunoreactive insulin levels in man. J Clin Invest 45: 228-236

31. Gerich JE, Karam JH, Forsham PH (1973) Stimulation of glucagon secretion by epinephrine in man. J Clin Endocrinol Metab 37: 479-481

32. Schade DS, Eaton RP (1977) The regulation of plasma ketone body concentration by counterregulatory hormones in man. I: Effects of norepinephrine in diabetic man. Diabetes 26: 989-996
33. Heimberg M, Fizette NB, Klausner H (1964) The action of adrenal hormones on hepatic transport of triglycerides and fatty acids. J Am Oil Chem Soc 41: 774-779

34. Bieberdorf FA, Chernick SS, Scow RO (1970) Effect of insulin and acute diabetes on plasma FFA and ketone bodies in the fasting rat. J Clin Invest 49: 1685-1693

35. Robertson RP, Smith PH (1976) Stress-induced inhibition of triglyceride secretion in vivo in Sand Rats. Metabolism 25: $1583-1590$

36. Shafrir E, Sussman KE, Steinberg D (1959) The nature of epinephrine induced hyperlipidemia in dogs and its modification by glucose. J Lipid Res 1: 109-117

37. Shafrir E, Sussman KE, Steinberg D (1960) Role of the pituitary and the adrenal in the mobilization of free fatty acids and lipoproteins. J Lipid Res 1: 459-465

38. Keller UJ, Chiasson L, Liljenquist JE, Cherrington AD, Jennings AS, Crofford OB (1977) The roles of insulin, glucagon, and free fatty acids in the regulation of ketogenesis in dogs. Diabetes 26: 1040-1051

39. Schonfeld G, Pfleger B (1971) Overproduction of very low density lipoproteins of the genetically obese hyperlipoproteinemic Zucker fatty rat. J Lipid Res 25 : 457-465

40. Eaton RP, Nye WH (1973) The relationship between insulin secretion and triglyceride concentration in endogenous lipemia. J Lab Clin Med 81: 682-695

41. De Oya M, Prigge WR, Grande F (1971) Suppression by hepatectomy of glucagon-induced hypertriglyceridemia in geese. Proc Soc Exp Biol Med 136: 107-110

42. Eaton RP (1973) The hypolipemic action of glucagon in experimental endogenous lipemia in the rat. J Lipid Res 14: 312-318

43. Vaughan M, Steinberg D, Pittman R (1964) On the interpretation of studies measuring uptake and esterification of $1-\mathrm{C}^{14}$ palmitate by rat adipose tissue in vitro. Biochim Biophys Acta 84: $154-159$

44. Amatuzio DS, Grande F, Wada S (1962) Effect of glucagon on the serum lipids in essential hyperlipemia and in hypercholesterolemia. Metabolism 11: 1240-1247

45. Salter JM (1960) Metabolic effects of glucagon in the Wistar rat. Am J Clin Nutr 8: 535-539

46. Smith HM, Weyer EM (eds) (1968) Diazoxide and the treatment of hypoglycemia. Ann NY Acad Sci 150: 191-467

47. Altszuler N, Hampshire J, Moraru E (1977) On the mechanism of diazoxide-induced hyperglycemia. Diabetes 26: 931-935

Received: February 27, 1979,

and in revised form: November 1, 1979

\section{R. Philip Eaton, M.D.}

University of New Mexico

School of Medicine

Department of Medicine

Albuquerque, NM 87131

USA 